\title{
PHASE TRANSITION DETERMINED BY ULTRASOUND IN SHAPE MEMORY MATERIALS
}

\author{
S. Stoimenov \\ Institute of Physics, Faculty of Natural Sciences and Mathematics \\ St.St. Cyril and Methodius University, P.O. Box 162, 1000 Skopje, R. Macedonia
}

(Received August 30, 2001; received in final form October 2, 2001)

\begin{abstract}
In principle, the shape memory effect is associated with thermoelastic martensitic transformation and reverse transformation. The unique feature of this shape memory materials is the formation of the high mechanical force due the thermal excitation. This specific thermal behaviour is most interesting for examination, from aspects of thermoelasticity. Shape memory refers to the ability of certain materials to "remember" the shape, even after rather severe deformations: once deformed at a low temperature (in their martensitic phase), these materials will stay deformed until heated, whereupon they will spontaneously return to their original, pre-deformation shape. The basis for the memory effects is that the materials can easily transform to and from martensite and reverse transformation. The incoming of thermal energy in the temperature region of the transformation changes the feature of elasticity. For this reason the value of the velocities and attenuation of ultrasound are changed. Using relationships from the theory of elasticity and values of the density and velocities of ultrasound it is possible to obtain the values of the elastic moduli $(E, K, G)$ and Poisson's ratio $\nu$. In this case it is possible to obtain complete information about the elastic, i. e. thermo-elastic state.
\end{abstract}

Key words: phase transition, shape memory effect, ultrasound, thermoelasticity, attenuation.

PACS number(s): 81.40.Jj, 81.70.Dw

\section{INTRODUCTION}

The most widely used shape memory material is an alloy of Nickel and Titanium called Nitinol. This particular alloy has excellent electrical and mechanical properties, long fatigue life, and high corrosion resistance. As an actuator, resulting in $\sim 1$ Joule/gm of work output, Nitinol is readily available in the form of wire, rod, and bar stock with transformation temperature in the range of $-100^{\circ}$ to $+100^{\circ}$ Celsius.

The type of transformation which occurs in the shape memory alloys is known as a martensitic transformation and changes the material from the high temperature form, called "austenit", to the low temperature form called "martensite". For a given alloy composition in a given annealed condition, the transforamation occurs at a very predictable, repeatable temperature. The transformation occurs because either one phase or the other is thermodynamically more stable than the other at that temperature. Also, because the material can change from one phase to the other with a simple shearing motion of the atoms within the crystal structure and no diffusion or large movements atoms is required, the transformation can occur virtually instantly. That is, as fast as heat energy can be put into or taken out of the material, the transformation (and memory) will occur.

The thermodynamic driving force which causes the materials to change to austenit upon heating is very strong - stronger than the yield strength of the alloy - and, therefore, the forces during shape recovery may be as high as the inherent strength of the austenite material.

Fortunately, the stress needed to deform the martensite is much less than the yield strength of the austenite
- in some case several times less. This leads to one of the most useful aspects of the shape memory alloys, that is, the force needed to deform a shape memory article while it is cooling to martensite or after it has finished cooling to martensite or after it has finished cooling may be much less than the force which the article can exert when it is heated and reverted to austenite. Thus, the work needed to deform the article in its low temperature form is much less than the work that can be extracted from it when it is heated. One therefore has a heat engine which can convert heat into useful work, either as one cycle element or as a cyclic engine.

The influence of composition and thermo mechanical processing on the functional properties is well understood and described in the literature earlier. The basic concept to remember is that in order to avoid plastic deformation during shape memory or pseudoelastic loading the martensitic and the $\beta$-phase have to be strengthened. NiTi alloys have the significant advantage that these techniques can be easily applied due to good ductility and a very interesting but complicated precipitation process [1].

\section{MECHANISM}

If steel in a high-temperature austenitic phase is quenched it will be generally hardened. After polishing and etching, observation with a microscope will show an extremely fine structure, which was first named "martensite".

It was later shown that this structure resulted from lattice transformation wholly without atomic diffusion. The face-centered cubic austenite transformed into lensshaped or plate-like regions with body-centered tetrag- 


\section{S. STOIMENOV}

onal lattices. The crystals created by such transformations are called "martensite" and lattice transformations without atomic diffusion are called "martensitic transformations" or simply "MTs". Diffusionless martensitic transformation has since been observed in many metals, alloys, and compounds other than steel. Today the term "martensitic transformation" is widely used, and signifies one type of phase transition in solids.

"Martensitic transformation" can be defined simply and precisely: a lattice transformation involving shearing deformation and resulting from cooperative atomic movement. The atoms within the lens or plate shaped areas in the parent phase are not shifted independently but undergo shearing deformation as a unit while maintaining a domino like coordination until the parent lattice transform into martensite. With this kind of cooperative movement of atom a 1-to-1 "lattice correspondence", persists between lattice points in parent phase and the points in the martensite phase. When the parent phase has a super lattice structure, this ensures that the martensite phase obtained from transformations maintaining such a lattice correspondence will have a specific super lattice.

From the thermodynamic point of view in $\mathrm{P}$ (atern) to $\mathrm{M}$ (artensitic) transformation, the chemical free energy of the $\mathrm{M}$ phase must be lower than that of the $\mathrm{P}$ (atern) phase. In this transformation, therefore it can be supposed that the chemical driving force for transformation is balanced without chemical energy. In other words, the growth and shrinkage of the martensite plate occur under a balance without chemical energy. In other words, the growth and shrinkage of the martensite plates occur under a balance between thermal and elastic effects, and thus transformation can be reversible. Martensites that exhibit such reversibility on cooling and heating are generally called thermo elastic martensites. Alternate prerequisites for their occurrence are (1) small lattice deformation for the transformation, (2) martensisites containing internal twins that can be easily the twined, and (3) martensites having an ordered structure that cannot be destroyed by slip.

\section{CHARACTERISTIC TEMPERATURES}

Some characteristics (phase, structure, properties, ets.) are drastically changed in the temperature region of transformations. As a result of this, the materials sometimes showed different behaviour.

The martensitic transformation that occurs in the shape memory alloys yields a thermoelastic martensite and develops from a high-temperature austenite phase with long-range order. The martensite typically occurs as alternately sheared platelets, which are seen as a herringbone structure when viewed metallographically. The transformation, although a first-order phase change, does not occur at a single temperature but over a range of temperatures that varies with each alloy system. The usual way of characterizing the transformation and naming each point in the cycle is shown in Fig. 1 . The trans- formation also exhibits hysteresis in that the transformations on heating and on cooling do not overlap. Hysteretic systems are not in thermodynamic equilibrium. In most instances they are driven very far from equilibrium. Their behaviour is the behaviour of systems with rugged free energy landscape in which thermal fluctuation are not sufficient to reach the absolute free energy minimum. The energy dissipation occurs in the passage from one minimum to another, in a sequence of repeatable results in large variations of the system response.

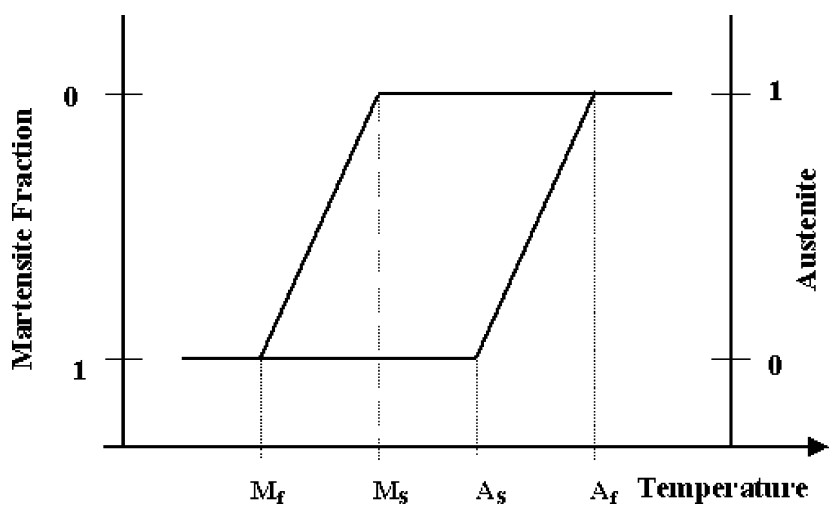

Fig. 1. Volume fraction versus temperature.

There are four fundamental characteristic temperatures defining a thermoelastic martensitic transformation; the martensite start temperature, $\mathbf{M}_{\mathbf{S}}$, at which martensite first appears in the austenite. The transformation proceeds with further cooling and is complete at the martensite finish temperature, $M_{\mathrm{f}}$. Below $M_{\mathrm{f}}$, the entire body is in the martensite phase, and a specimen typically consists of many regions each containing a different variant of martensite. The boundaries between the variants are mobile under small applied loads. With heating, the austenite start at temperature $A_{\mathrm{S}}$, is the temperature at which austenite first appears in the martensite. With further heating, more and more of the body transforms back into austenite, and this reverse transformation is complete at the austenite finish temperature, $A_{\mathrm{f}}$. Above $A_{\mathrm{f}}$, the specimen is in the original undistorted state. The evolution of the volume fraction of the martensite with temperature is shown schematically in Fig. 1.

Most of the transformation occurs over a relatively narrow temperature range, although the beginning and end of the transformation during heating or cooling actually extends over a much larger temperature range. For complete analysis of the hysteresis diagrams, usually, other three characteristic temperatures are used: $T_{0}, M_{\mathrm{d}}$ and $A_{\mathrm{d}}$. By definition:

(i) $T_{0}$ is the temperature of the thermodynamical equilibrium.

(ii) $\mathrm{M}_{\mathrm{d}}$ is the temperature below which martensite occurs and exists not only as a consequence of the change temperature, but also by the mechanical stress.

(iii) At temperature $A_{d}$ the system has possibility to form initial phase not only as a consequence of heating but also with mechanical stress. 
The factors influencing the critical temperatures are:

- chemical fractions,

- stress and deformation.

- thermomechanical cycling,

- thermical cycling,

- condition of sintering processes for sintering materials, ets.

The cycle is described in the following way. At a temperature above $M_{\mathrm{s}}$, the specimen is entirely in the austenite phase. By cooling below $M_{\mathrm{f}}$ transformation the specimen entirely is in the martensite phase, but the macroscopic volume of the specimen has not changed a condition known as self-accommodation. With small loads the specimen can be easily deformed, and the deformed shape remains after removing the loads. Heating to above $A_{\mathrm{f}}$ causes the reverse transformation to occur and the specimen returns to its original undistorted state. TiNi alloys possess excellent properties as regards both mechanical strength and shape memory characteristics. Considering this point, TiNi shape memory alloys produced using powder materials have been a subject of interest. The methods employed for their productions are of two kinds, i. e., using prealloy metal powder [1], and using elemental metal powders.

\section{STRUCTURE}

All reports agree that the parent phase of TiNi has a BCC B2 structure like that of CsCl. As for the crystal structure of the martensite phase in TiNi alloys a large number of researches have proposed different models. However the results of research which used different methods all agree on the point that the unit cell for Ti$49.75 \mathrm{at} \% \mathrm{Ni}$, of the martensite phase is monoclinic although there are discrepancies in the absolute values of lattice constant [2].

The reason that the shape memory effect can be used in a cyclic device where it must exhibit the shape recovery many times is that the shape memory deformation mode in the martensite phase is non-damaging to the crystal structure. In normal metals deformation occurs by the motion of dislocations and atomic planes actually slide over one another and assume a new crystal position. There is no "memory" in crystal for where the atoms were before they moved, and increased tangles of dislocations occur in the crystal due to the deformation. These tangles make further deformation more difficult even deformation which attempts to restore the original shape of the crystal.

The influence of composition and thermo-mechanical processing on the functional properties is well understood and described in literature earlier. The basic concept to remember is that in order to avoid plastic deformation during shape memory or pseudoelastic loading the martensitic and the $\beta$-phase have to strengthen. NiTi alloys have the significant advantage that these techniques can be easily applied due to good ductility and a very interesting but complicated precipitation process $[3]$.
The addition of a third element opens even more possibilities for adapting binary NiTi alloys toward more specific needs of applications. Adding a third element implies a relative replacement of $\mathrm{Ni}$ and/or Ti. Therefore it must be always very well indicated which atom $\mathrm{Ni}$ or Ti or both replaced by the third element.

Alloying third elements will influence not only the transformation temperatures but will also have an effect on hysteresis, strength, ductility shape memory characteristics and also on the $\mathrm{B} 2 \rightarrow(\mathrm{R}) \rightarrow(\mathrm{B} 19)$ sequence. The influence of several elements has been already described in [4-6]. More application oriented, one can distinguish four purposes to add third elements:

1. To decrease $(\mathrm{Cu})$ or increase $(\mathrm{Nb})$ hysteresis.

2. To lower the transformation temperatures (Fe, Cr, $\mathrm{Co}, \mathrm{Al})$.

3. To increase the transformation temperatures (Hf, $\mathrm{Zr}, \mathrm{Pd}, \mathrm{Pt}, \mathrm{Au})$.

4. To strengthen the matrix (Mo, W, O, C).

Some of the ternary alloys have been developed for large-scale applications. Ternary $\mathrm{Ti}-\mathrm{Ni}-\mathrm{Cu}$ alloys are certainly as important as binary TiNi.

The thermoelastic martensites are characterized by their low energy and glissile interfaces, which can be driven by small temperature or stress changes. As a consequence of this, and of the constraint due to the loss of symmetry during transformation, thermoelastic martensites are crystallographically reversible.

\section{THERMOMECHANICAL BEHAVIOUR}

The herringbone structure of athermal martensites essentially consists of twin-related, self-accommodating variants (Fig. $2 \mathrm{~b}$ ). The shape change among the variants tends to cause them to eliminate one another. As a result, little macroscopic strain is generated. In the case of stress-induced martensites, or when stressing a selfaccommodating structure, the variant that can transform and yield the greatest shape change in the direction of the applied stress is stabilized and becomes dominant in the configuration (Fig. 2c). This process creates a macroscopic strain which is recoverable as the crystal structure reverts to austenite during reverse transformation.

The mechanical properties of the shape memory alloys vary greatly over the temperature range spanning their transformation. This is seen in Fig. 2c,d, where simple stress-strain curves are shown for a nickel titanium alloy that was tested in tension below, in the middle of, and above its transformation temperature range. The martensite is easily deformed to several percent strain at quite a low stress, whereas the austenite (high temperature phase) has much higher yield and flow stresses. The dashed line on the martensite curve indicates that upon heating after removing the stress, the sample remembered its unstrained shape and reverted to it as the material transformed to austenite. No such shape recovery is found in the austenite phase upon straining and heating, because no phase change occurs. 


\section{S. STOIMENOV}

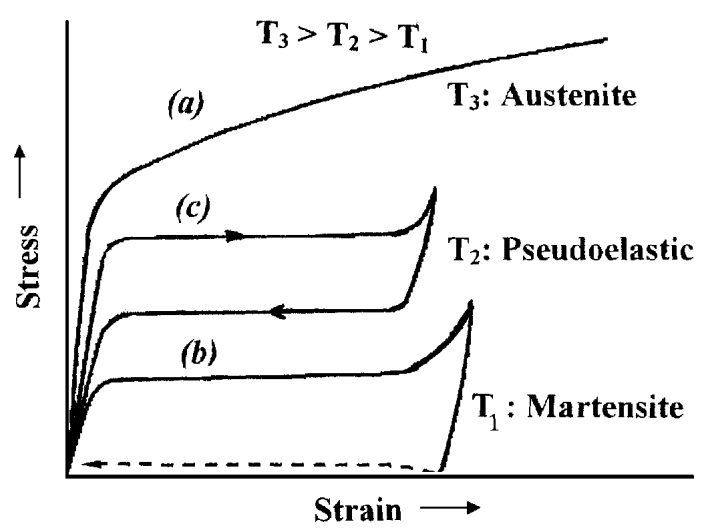

Fig. 2. Typical stress-strain curves at different temperatures relative to the transformation showing: (a) austenite, (b) martensite, and (c) pseudoelastic behaviour.

An interesting feature of the stress-strain behaviour is seen in Fig. 2c, where the material is tested slightly above its transformation temperature. At this temperature, martensite can be stress-induced. It then immediately strains and exhibits the increasing strain at constant stress behaviour, seen in AB. Upon unloading, though, the material reverts to austenite at a lower stress, as seen in line CD, and shape recovery occurs, not upon the application of heat but upon a reduction of stress. This effect, which causes the material to be extremely elastic is known as pseudo-elasticity. The pseudoelasticity is nonlinear. The Young modulus is therefore difficult to define in this temperature range as it exhibits both temperature and strain dependences.

It is possible in some of the shape memory alloys to cause two-way shape memory, that is the shape change occurs upon both heating and cooling. The amount of this shape change is always significantly less than that obtained with one-way memory and, therefore. a very little stress can be exerted by the alloy as it tries to assume its low-temperature shape. The heating shape change can still exert very high forces, as in the case of one-way memory.

\section{CHARACTERIZATION METHODS}

There are more major methods of characterizing the transformation in SMAs and a large number of minor methods that are only rarely used and will not be discussed.

The most direct method is by differential scanning calorimetry (DSC). This technique measures the heat absorbed or given off by a small sample of the material as it is heated and cooled through the transformation temperature range. The sample can be very small, such as a few milligrams, and because the sample is unstressed, this is not a factor in the measurement. The endotherm and exotherm peaks, as the sample absorbs or gives off energy due to the transformation, are easily measured for the beginning peak, and end of the phase change in each direction.
The second method often used is to measure the resistivity of the sample as it is heated and cooled. The alloys exhibit interesting changes and peaks in the resistivity (by up to $20 \%$ ) over the transformation temperature range; however, correlating these changes with measured phase changes or mechanical properties has not always been very successful. Also, there are often large changes in the resistivity curves after cycling samples through the transformation a number of times. Thus, resistivity is often measured as a phenomenon in its own right, but this is rarely used to definitely characterize one alloy versus another.

The most direct method of characterizing an alloy mechanically is to prepare an appropriate sample, then apply a constant stress to the sample and cycle it through the transformation while measuring the strain that occurs during the transformation in both directions. The obtained curve shows is the direct information one obtains from this test. Finally, the stress-strain properties can be measured in a standard tensile test at a number of temperatures across the transformationtemperature range, and from the change in properties the approximate transformation-temperature values can be interpolated.

The transparency of ultrasound is in a direct correlation with the elastic state of the materials. This is very important for an obtaining of information about the thermo-elastic state in materials with shape memory effect. For this purpose it is proposed to investigate the transparency of ultrasound with warming and cooling through interval of $\mathrm{M} / \mathrm{A}$ and reverse transformation.

\section{EXPERIMENTAL PROCEDURE}

The samples for examination were prepared from specially prepared powder mixtures of metals (Ni-99.8\%pure, Cu-99.7\%-pure and Ti-99.5\%-pure, produced in MERCK-Company), by two faces cold pressing and sintering $[7,8]$. The addition of the third elements opens even more possibilities for adapting binary NiTi alloys towards more specific needs for applications. Adding of the third element implies relative replacement of $\mathrm{Ni}$ and/or Ti. Therefore it must be always very well indicated which atom of $\mathrm{Ni}$ or $\mathrm{Ti}$, (or both) is replaced with the third element. In this case the volume, structural magnetic thermoelastic and other properties are changed.

The diameter of the obtained cylindrical samples was $\sim 17.5$ and the length was about $18 \mathrm{~mm}$. The maximum value of the pressure on the mixture was $400 \mathrm{MPa}$. The samples were sintered in argon atmosphere at the temperature of $1073,1123,1173,1223$, and $1273 \mathrm{~K}$, for the time of $3.6 \mathrm{ks}$. The complete procedure of compaction and sintering, starting from pure metal powders of $\mathrm{Ti}$ and $\mathrm{Ni}$, trough different processes of obtaining samples for examination are presented in Fig. 3.

The market effect of the shape memory materials is the conversion of the low temperature of thermal energy to mechanical one. Without the elastic deformation using ultrasound, it is possible to register the elastic (i.e. 
thermo-elastic) changes through the austenit/martensit and reverse temperature transformation. In this region the values of velocities and attenuation showed hysteresis behaviour. These results are most important for the determination of the interval of the temperature transformations, for decrease or increase of the hysteresis form, for hysteresis shift and for more other aspects.

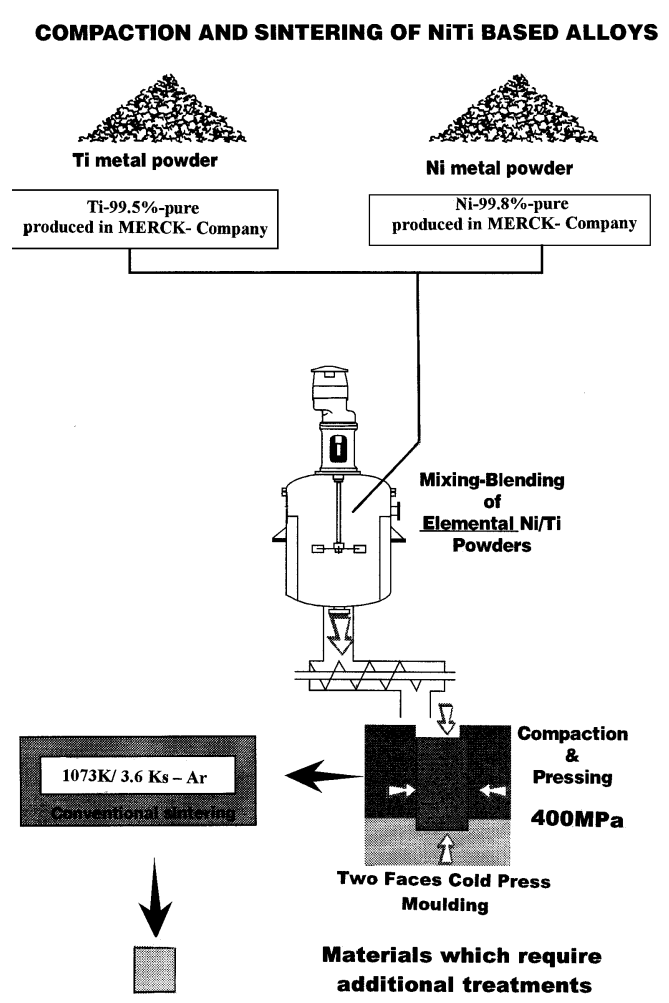

FINAL SELFSTANDING COMPONENT

Fig. 3. Block-scheme of same procedure tor prepared samples examinations.

\section{ULTRASONIC METHOD AND TECHNIQUES}

The velocities of longitudinal $(v l)$ and transverse $(v t)$ ultrasonic waves were measured by Pulse-echo overlap method proposed by Papadakis [9], with technique and equipment detail described earlier [10,11]. The experimental values of the velocities were measured in interval of temperature from 290 to $425 \mathrm{~K}$. The functional block diagram of the equipment with typical instrumentation arrangement for the simultaneous measurement of the velocities and attenuation is presented in Fig. 4. This experimental technique was completed and adapted [10] for measuring the velocities and attenuation of the ultrasonic waves in region of $\mathrm{A} / \mathrm{M}$ transformation with added mini furnace.

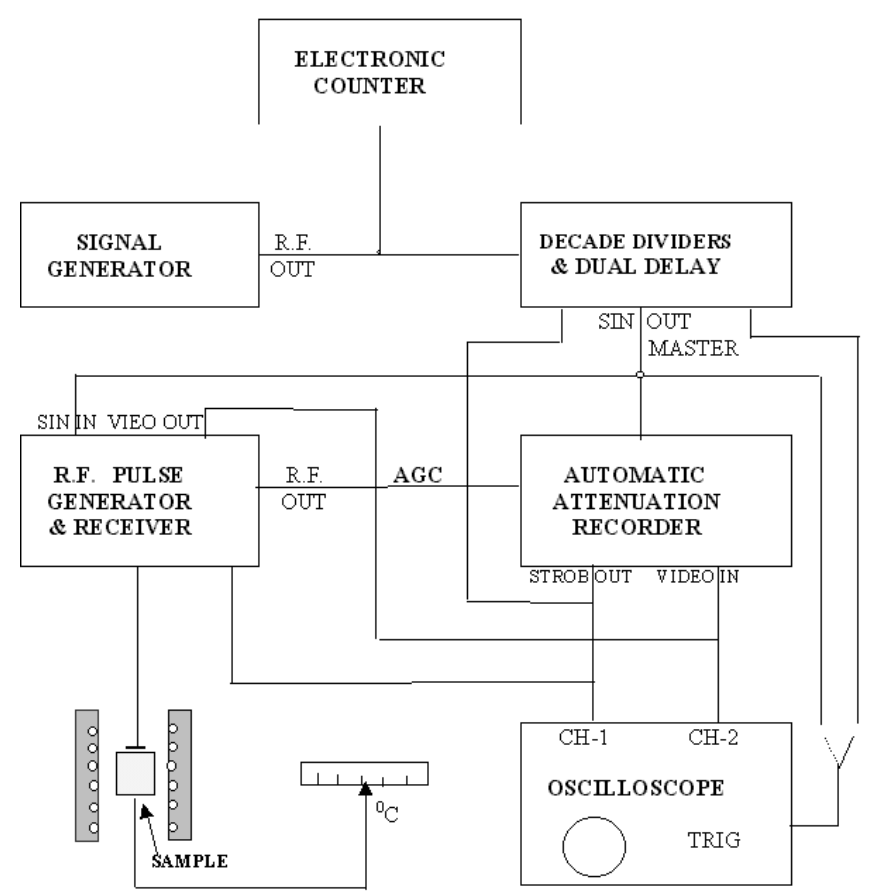

Fig. 4. Block-diagram for ultrasonic equipment.

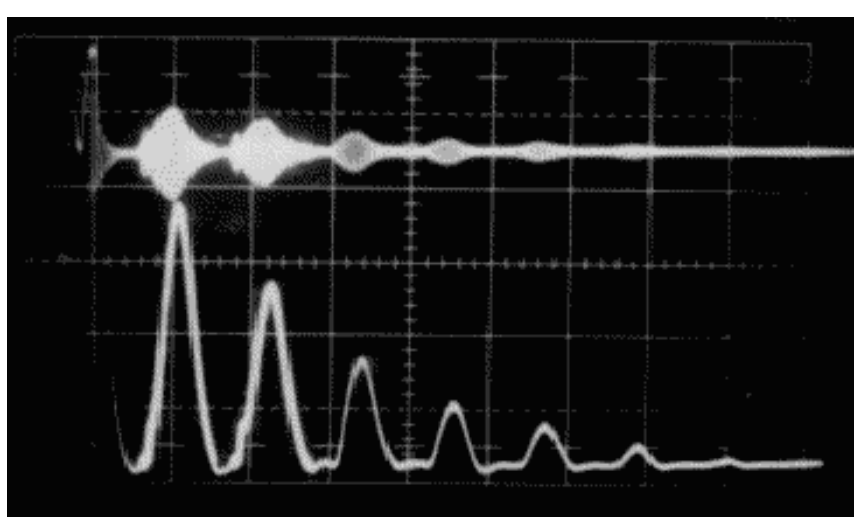

Fig. 5. Selected 1 and 2 echoes (up: velocities, down: attenuation).

A typically used echo patterns (up for velocities, down for attenuation) are shown in Fig. 5. The velocities of ultrasonic waves were measured at $10 \mathrm{MHz}$ for longitudinal, and $6 \mathrm{MHz}$ for transversal waves for all samples, and values of attenuation at $5 \mathrm{MHz}$. The PZT transducers were bounded to the samples with argentums grease on either of two parallel faces of the sample. By standard relationships from the theory of elasticity [12], using the values of the density $\rho$ of the samples and velocities of the ultrasonic waves $(v)$, the elastic moduli (Young's modulus $(E)$, shear modulus $(G)$, bulk modulus $(K)$ and Poisson's ratio $(\sigma))$ were determined.

Actually, the values of velocity $v$ were determined by relationship $v=2 l / t$, where $l$ denotes the specimen length and $t$ denotes the round-tripe time for an ultrasonic pulse between two flat-and-parallel specimen faces. 


\section{S. STOIMENOV}

Practically $t$ was determined as a reciprocal value of frequency, which was registered from electronic counter (see Fig. 4), at the moment of realization optical overlaps and phase-tuned echoes (Fig. 6).

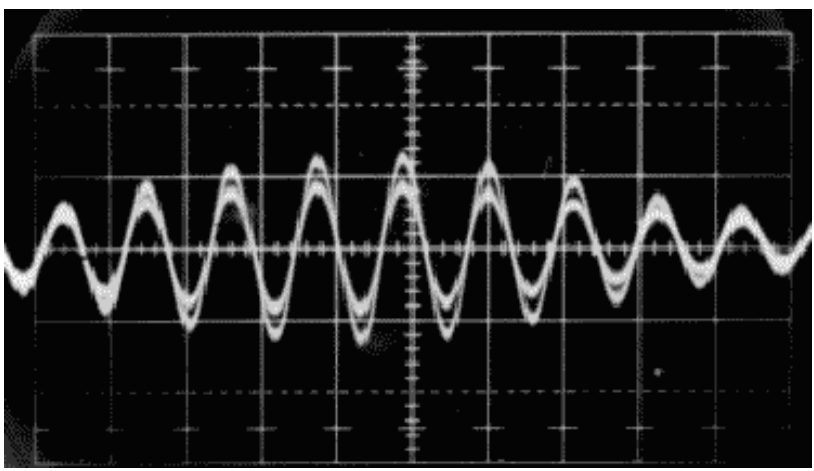

Fig. 6. Some echo pattern for examined materials.

\section{EXPERIMENTAL RESULTS AND DISCUSSION}

The transparency of ultrasound is in direct correlation with the elastic state of the examined materials. This is most important for obtaining information about thermoelastic state in materials with shape memory effect.

For the purpose of this transformation it is proposed to investigate the transparency of ultrasound with warming and cooling through interval of $\mathrm{M} / \mathrm{A}$ and reverse transformation. The comparative presentation of experimentally obtained values of velocities for longitudinal and $(\mathrm{Vl})$ and transverse $(\mathrm{Vt})$ ultrasonic waves for different temperatures of sintering $(1073,1123,1173,1223$ and $1273 \mathrm{~K}$ ) for heating and cooling in examined interval are given in Fig. 8 and Fig. 9, respectively. From last two series of diagrams for both type of velocities ( $V l$ and $V t$ ), sintered in different temperature conditions showed similar hysteresis behaviour. By increase of temperature of sintering, the values of the velocities in the beginning are increased, after that their values decrease. At first sight all diagrams of the longitudinal and transverse ultrasonic waves obtained in presented examination show similar behaviour.

The values of attenuation of longitudinal $(A l)$ and transverse $(A t)$ ultrasonic waves in TiNi compound, sintered at $1073 \mathrm{~K}$, in temperature interval from 290 to $425 \mathrm{~K}$ were obtained from the measurement with described equipment. The values of attenuation ( $A l$ and $A t$ in $\mathrm{dB}$ ) were measured directly from attenuate. The diagrams for attenuation ( $A l$ and $A t)$ are presented in the Fig. 10.

With the increase of the concentration of the $\mathrm{Cu}$, from $2.5,5,10,15$ and $20 \% \mathrm{Cu}$, the hysteresis for both types of velocities are shifted and decreased [7]. The velocity values of the transverse ultrasonic waves (Fig. 6) generally increase with addition of Copper until $15 \% \mathrm{Cu}$. For this behaviour of the diagrams for $20 \% \mathrm{Cu}$, for both types of velocities, the velocity values are smaller than the values for $15 \% \mathrm{Cu}[13]$. The diagrams of the elastic moduli (Bulk modulus $K$ and the Young modulus $E$ ) are presented in Fig. 12.
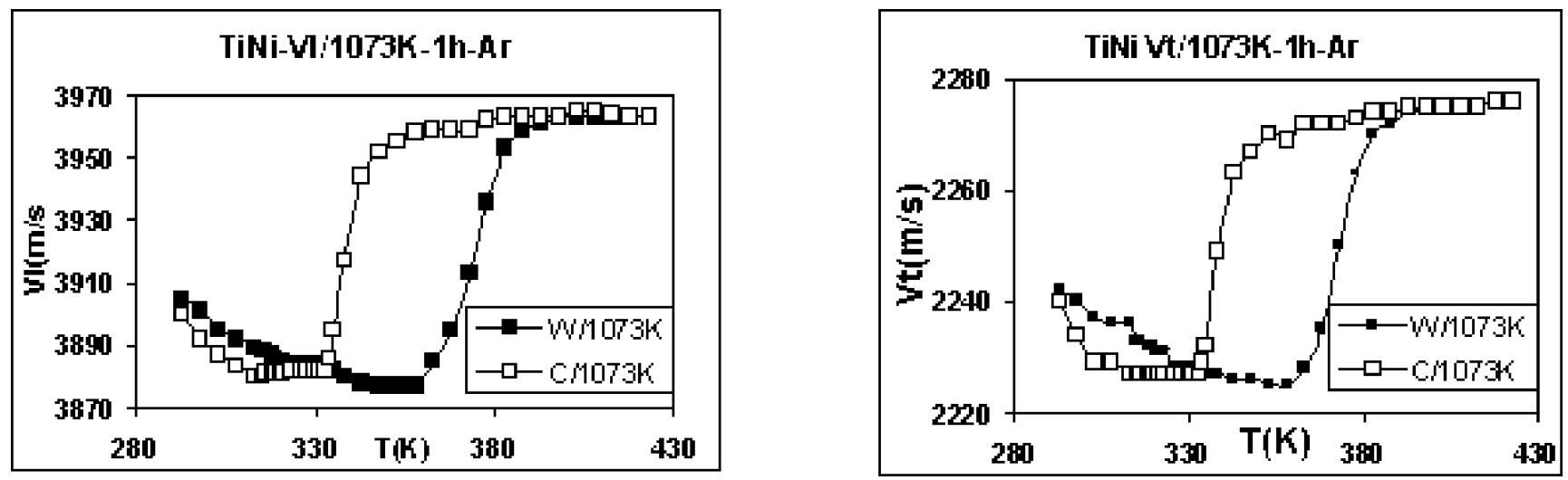

Fig. 7. The diagrams of the longitudinal $(v l)$, and transverse $(v t)$ ultrasonic waves as a function of temperature in regions of phase transition.

It is evident from the previous figures, that the diagrams of velocities, attenuation and elastic moduli have a hysteresis form in the same interval of temperature, i.e., in the same interval of transformation. The curves on the right side of the hysteresis (see Figs. 7-12) curve with the experimental points and present diagrams of the heating, whereas the curves on the left side of the hystereses present diagrams of the cooling. 


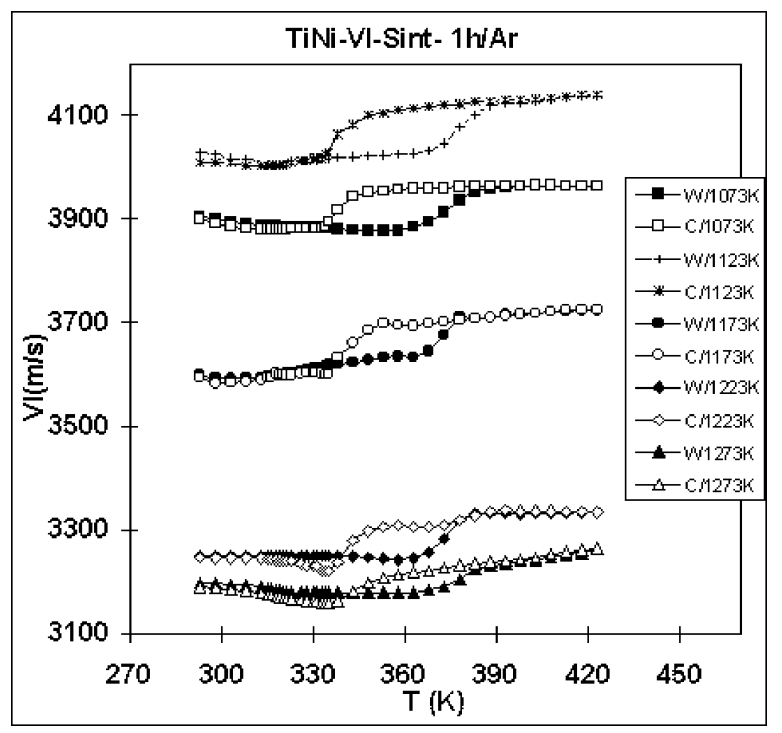

Fig. 8. The diagrams of the longitudinal ( $v l)$ ultrasonic waves for different temperatures of sintering.

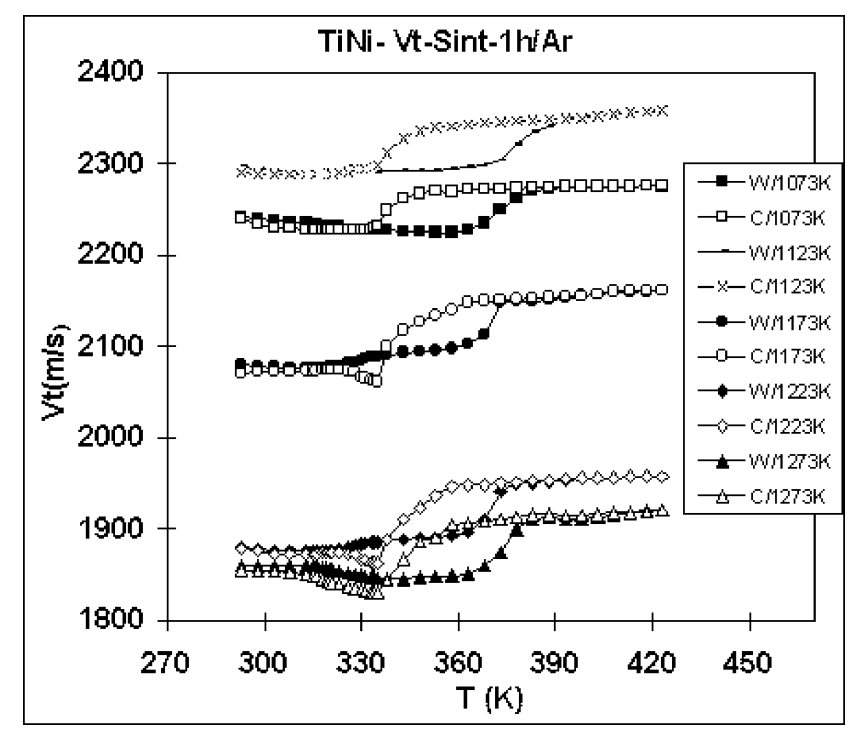

Fig. 9. The diagrams of the transverse $(v t)$ ultrasonic waves for different temperatures of sintering.
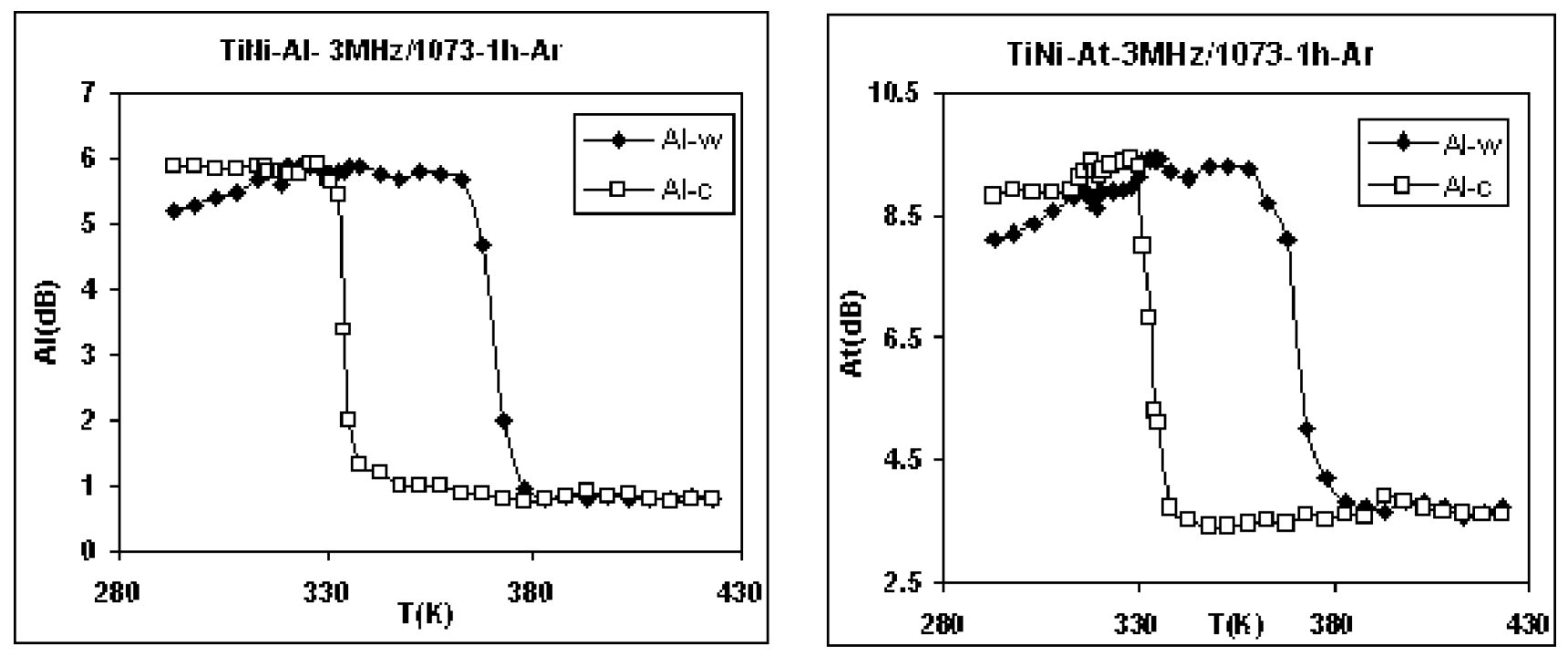

Fig. 10. The diagrams for attenuation of the longitudinal $(A l)$ and transverse $(A t)$ ultrasonic waves as a function of temperature.

The values of attenuation $(A$ in $\mathrm{dB})$ were measured directly from attenuate and the coefficient of absorption $(\alpha)$ was calculated. Depending on the quality of the material, its structural conditions and its ultrasonic frequency there may be several different absorption mechanisms

$$
\alpha=\sum_{i} \alpha_{i}
$$

where the subscript $i=(H, R, M, \ldots)$ refers to the mech- anism: elastic hysteresis - $H$, Raleigh's scattering $R$, magneto elastic effect $-M$, diffraction losses $-D$, porosity $-P$, and others.

The values of attenuation ( $A$ in $\mathrm{dB}$ ) were measured directly from attenuate, and the coefficient of absorption $(\alpha)$ was calculated by the relation:

$$
\alpha=A_{1, n} / 2 \operatorname{Ln}(n-1),
$$

were $L$ is the length of the sample and $n$ is the number of 


\section{S. STOIMENOV}

seconds of the selected and intensified echo. The experimental absorption values were corrected by the quantity of absorption due to the diffraction losses. (In Fig. 5 se- lected and intensified echoes are 1 and 2). From the $n$ obtained values, the average value of coefficient of absorption was found.

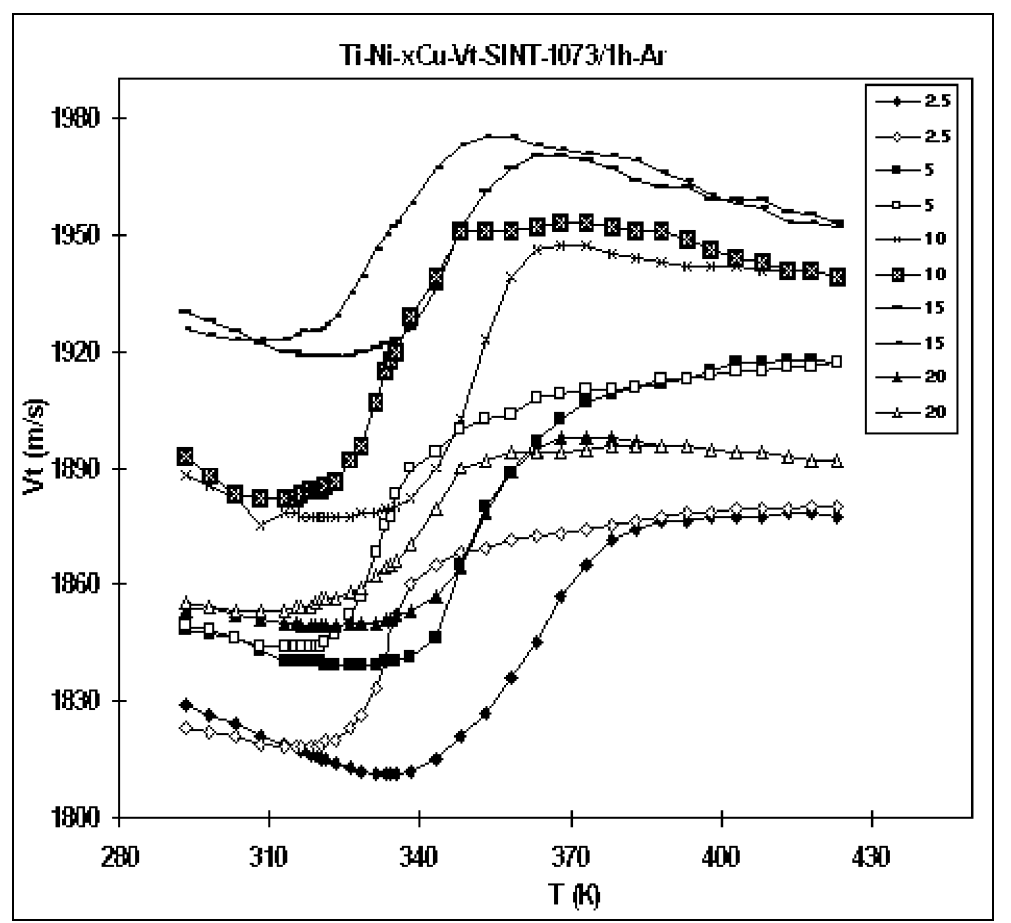

Fig. 11. The diagrams of the transverse $(v t)$ ultrasonic waves as a function of temperature, with different concentration of $\mathrm{Cu}$
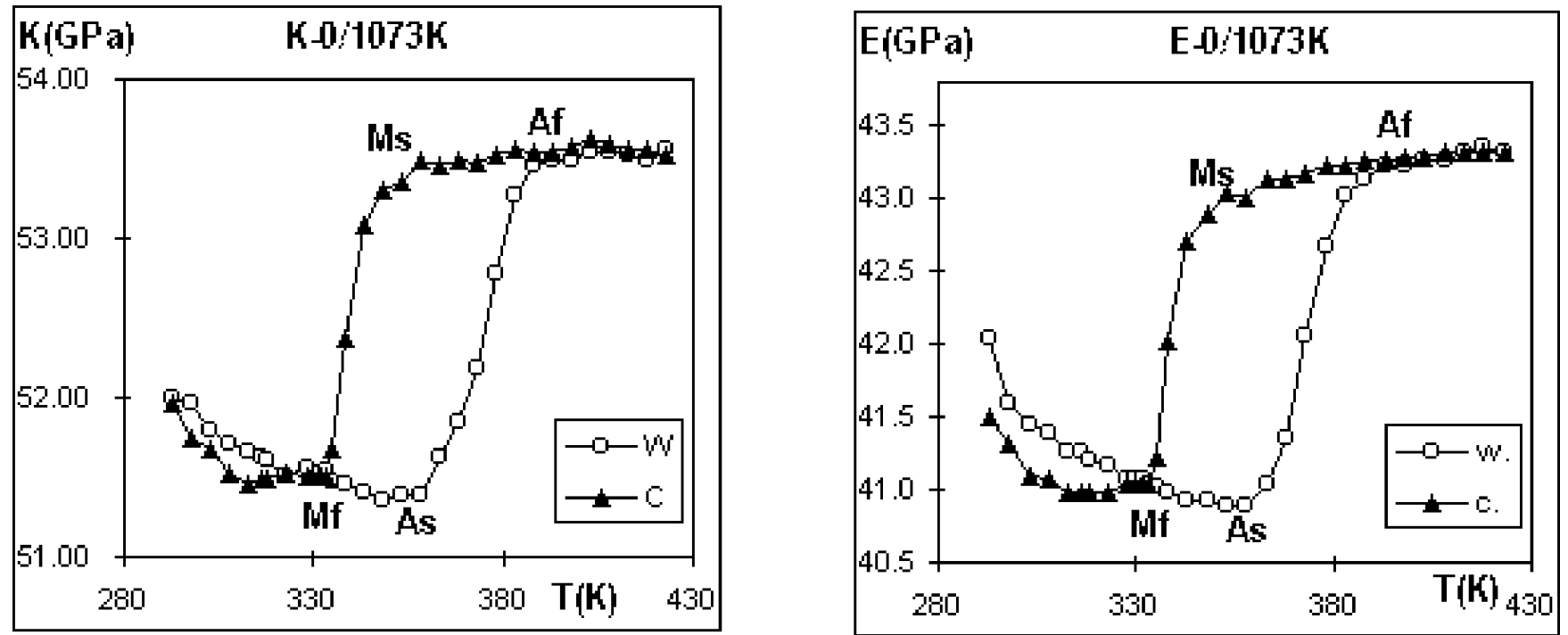

Fig. 12. The diagrams of the Bulk Modulus $(K)$ and Young modulus $(E)$.

Using the theory of elasticity [12], the values of the density $(\rho)$ of the sample and the longitudinal $\left(\nu_{l}\right)$ and transverse $\left(\nu_{t}\right)$ velocities of the ultrasonic waves, the bulk modulus $(K)$ and Young modulus $(E)$ were determined by the following relationships:

$$
K=\frac{\rho}{3}\left(3 \nu_{l}^{2}-4 \nu_{t}^{2}\right),
$$




$$
E=\rho \frac{\nu_{t}^{2}\left(3 \nu_{l}^{2}-4 \nu_{t}^{2}\right)}{\nu_{l}^{2}-\nu_{t}^{2}}
$$

All presented diagrams in Figs. 7-12 give the typical transformation curves for materials with shape memory effect. The "critical points" of the transformation (see Figs. 7-12) are: the martensite starting temperature during cooling $\left(M_{\mathrm{S}}\right)$, martensite finish temperature $\left(M_{\mathrm{f}}\right)$, the austenite starting temperature during heating $\left(A_{\mathrm{S}}\right)$, and the austenite finish temperature $\left(A_{\mathrm{f}}\right)$. The lowest value of the velocities, attenuation and elastic moduli at $M_{f}$-point can indicate pseudoelastic state of the examined materials.

\section{SUMMARY}

The phase transition in the examined shape memory materials is accompanied with temperature hystersis, i. e., the diagrams of heating and cooling do not overlap. The examined samples were prepared from powder particle of Titanium Copper and Nickel, by the previously described method of powder methodology. The velocities of ultrasound were measured by the pulse echo overlap method, and the total values of attenuation were obtained directly from ultrasonic equipment. The elastic moduli were calculated in compliance with the theory of elasticity. The information about thermoelastic behaviour was obtained, with thermal treatment trough the temperature of transformation.

From the analysis and the comparison of the obtained hysteresis curves in materials with shape memory effect, it is possible to determine the most important thermoelastic behaviour in the interval of the temperature transformation. It is noticed that the thermoelastic state and the form of hysteresis are determined under the condition of preparation and presence of third component.
[1] D. Aslanidis, in Proceedings of the First European Conference on Shape Memory and Superl. Technologies (SMST-99), 5-9 September, Antwerp Zoo, Belgium (Antwerp Zoo, 1999), p. 384.

[2] K. Otsuka, T. Suvamura, K. Shimizu, Phys. Status Solidi 5, 457 (1971).

[3] M. Nishida, C. M. Waymanand, T. Hanna, Met. Trans. A 17, 1505 (1986).

[4] K. H. Eckelmeyer, Scripta Met. 10, 667 (1976).

[5] T. Honma et al., in Proceedings ICOMAT-79 (Cambrige, USA, 1979) p. 259.

[6] V. N. Kachin, Revue Phys. Appl. 24, 733 (1989).

[7] S. Stoimenov, A. Nikolovski, Z. Stojanov, Proc. Supl.
BPL 5, 510 (1997).

[8] S. Stoimenov, A. Nikolovski, Z. Stojanov, Proc. Supl. BPL 5, 642 (1997).

[9] E. Papadakis, J. Acoust. Soc. Am. 42, 1045 (1967).

[10] S. Stoimenov, M. Milosevski, M. M. Ristic, Sintering and Materials, (International Academic Publishers, 1995).

[11] S. Stoimenov, M. Milosevski, Science of Sintering 28 (2), 91-98 (1996).

[12] L. D. Landau, E. M. Lifshiz, Theory of Elasticity (Pergamon Press, London, 1959) p.13 and p. 99.

[13] S. Stoimenov, A. Shytula, Z. Stojanov, A. Nikolovski, Phys. Macedonica 50, 79 (2000).

\title{
ФАЗОВИЙ ПЕРЕХІД, ЯКИЙ ВИЗНАЧАЕТЬСЯ ЗА ДОПОМОГОЮ УЛЬТРАЗВУКУ В МАТЕРІЯЛАХ З ПАМ'ЯТТЮ ФОРМИ
}

\author{
С. Стоіменов \\ Інститут фізики, факультет природничих наук і математики \\ Університет Сб. Кирила і Мефодія, пошт. скринька, 162, 1000, Скоп'є, Македонія
}

\begin{abstract}
Назагал, ефект пам'ятання форми пов'язаний з термопружним мартенситним та зворотним перетворенням. Унікальною особливостю таких матеріялів з пам'яттю форми є утворення великої механічної сили під час дії теплового збудження. Ця специфічна температурна поведінка найцікавіша для дослідження 3 точки зору термопружности. Пам'ятання форми означає здатність певних матеріялів пам'ятати форму навіть після досить жорстких деформацій: здеформовані при низьких температурах (у мартенситній фазі), ці матеріяли залишатимуться такими до нагрівання, після чого вони самі по собі повернуться в початкову, недеформовану, форму. Основою для ефектів пам'яті $\epsilon$ те, що ці матеріяли можуть легко зазнавати мартенситного перетворення та переходити в попередній стан. Теплова енергія, яка надходить в температурну ділянку перетворення, змінюе особливості пружности. Через це швидкість та величина загасання ультразвуку змінюється. Використовуючи співвідношення з теорії пружности та значення густини $\mathbf{i}$ швидкостей ультразвуку, можна отримати значення пружних модулів $(E, K, G)$ та коефіщієнт Пуассона $\nu$. В цьому випадку можна одержати інформацію про пружний, тобто термопружний, стан.
\end{abstract}

